\title{
On the Full Actualization of Psychology in Business
}

\author{
Dr. Karol M. Wasylyshyn
}

Leadership Development
Copyright 2001 by the Educational Publishing Foundation and the Society of Consulting Psychology $1061-4087 / 01 / \$ 5.00$
DOI: $10.1037 / 1061-4087 . .53 .1 .10$
Consulting Psychology Journal: Practice and Research, Vol. 53, No. 1, 10-21106 www.APA.org

This article may not exactly replicate the final version published in the APA journal. It is not the copy of record. 


\title{
ON THE FULL ACTUALIZATION OF PSYCHOLOGY IN BUSINESS
}

\author{
Karol M. Wasylyshyn, Psy.D. Leadership Development
}

\begin{abstract}
The demands of work in this current atmosphere of globality, complexity, fierce competition, information technology, and employees' varied responses to it all -constitute an unprecedented opportunity for psychologists consulting to business. Ten trends are presented to illustrate the distinctive impact psychology could have in the workplace...IF. Absent reinvention within psychology, the author questions the likelihood of psychology actualizing its full potential in the workplace.
\end{abstract}

Karol M. Wasylyshyn, Psy.D., is president of Leadership Development, a management consulting firm specializing in applications of psychology in business. She is a member of the coaching faculty in The Wharton School's Advanced Management Program, an adjunct professor of clinical psychology at Widener University and was appointed to the University's Board of Trustees in 1995. Since 1982, Wasylyshyn has profiled and coached hundreds of senior executives throughout the world. She is also in clinical practice.

Correspondence concerning this article should be addressed to Karol $\mathrm{M}$. Wasylyshyn, 431 Chestnut Street, Philadelphia, Pennsylvania 19106 or kwasylyshyn@erols.com. 
ON THE FULL ACTUALIZATION OF PSYCHOLOGY IN BUSINESS

I am still learning.

Michelangelo

In the September 1999 issue of the APA Monitor, a column by Richard M. Suinn, then APA President, bore this provocative headline: What if psychology had a revolution? He then posed a series of intriguing questions in the areas of education (What if terminal master's degrees were not offered?), science (What if researchers formed listserv consortiums to collaborate on data collection?) and practice.

Regarding practice, I have spent nearly 20 years consulting to Fortune 500 companies and while I would not call for a revolution, a reinvention seems warranted. A reinvention seems warranted because an effective response to current people issues in business requires the merged expertise of psychologists from varied backgrounds - in addition to that of human resource practitioners and the experience of line managers. Psychologists need to diminish interdivisional debate about who should deliver what service(s) and focus instead on increasing synergy and collaboration with a broad range of colleagues. In doing so, we are likely to advance the impact of psychology in the workplace.

Following on Suinn's provocative "what-if's," I pose this question:

\section{What if psychology actualized its full potential in the workplace?}

This question reflects my view that psychology is still at an early stage of its influence on workplace leadership, policies, and practices. If the full potential of psychology in this practice area is to be actualized, psychologists must accelerate their efforts in two critical ways. First, we must expand greatly our presence in workplace settings throughout the world -- by elevating executives' understanding of the lasting power and utility of established psychological consulting services. Second, we must create and deliver new, targeted services that both enhance psychology's tradition of helping individual employees, and aid organizations in achieving success.

Through our consultative engagements with senior executives, in particular, we influence leader behavior, and the creation of workplace policies and practices that effect the human condition of hundreds, if not thousands of people. As psychology actualizes its potential in the workplace, it becomes a learning, healing, humanizing vehicle for an emotionally healthy and literate society, as well as a distinctive management tool. It achieves the stature it deserves as an essential resource. Increasingly, psychologists become the consultants of choice for a wide range of human resource challenges. 
Further, the emergence of certain trends in business -- to be described below -heightens the need for the application of psychology in business. Our substantive and sustained response to these trends will require expertise from a range of psychological perspectives including $\mathrm{I} / \mathrm{O}$, clinical, counseling, and consulting psychology. I can envision the emergence of the "consulting psychologist in residence" or Chief Psychology Officer (CPO) taking his/her place on corporate management teams beside already emerging roles such as Chief Knowledge Officer (CKO). While we are some distance from that, psychologists have much more to offer business now - IF we stay focused on the crucial issues, bring the best of all that psychology has to offer, and customize interventions that add value for both employees and their employers.

A related issue is the need for consulting psychologists to help establish other psychologists who are interested in this practice area. I have some concern that many established consulting psychologists remain too retentive about what we have, too mysterious about what we know, and for those who are inclined to bring along other consultants, too busy to be the teachers, supervisors, mentors, and marketing guides we need to be to assist others in "breaking into" and building successful consulting practices.

A poignant moment I experienced during a presentation at the 1999 APA national convention underscored this state of affairs. After I had encouraged audience members to consider workplace consultation as a viable direction for career expansion, one psychologist said, "I've spent 15 years in clinical practice; I believe I can do this work and I want to do it but I can't get enough concrete information from psychologists doing it. I don't think I can learn enough on my own. I feel like I need a boot camp to get started."

While a discussion of the complex training, supervision, and practice issues related to this practice area is not the objective of this article, we need to accelerate the dialogue about how to foster the necessary changes in training, supervision, and practice models if psychology is to secure its distinctive place in business consultation. This is true at both the graduate and post-graduate levels. The 1999 announcement of the first doctoral program in consulting psychology at the California School of Professional Psychology (San Diego) -- a curriculum blending individual, group, and organizational orientations -- may be indicative of forthcoming training changes that must occur if psychologists are to be prepared fully for this practice area.

The primary purpose of this article is to state why I believe this is an unprecedented time of opportunity -- largely untapped opportunity -- for psychologists who are interested in and/or are already consulting to the workplace. Through this discussion, it is my hope that more psychologists will be encouraged to pursue this practice area; that established consultants will rivet their work on current, pressing needs of people in the workplace; and, that 
experienced consultants will become more active in supporting the efforts of other psychologists who are drawn to this important work.

\section{Ten Trends that Bode Well for the Application of Psychology in Business}

There are at least ten trends that bode well for psychologists consulting to business. These trends have been identified through my ongoing conversations and collaboration with senior human resource and line executives in multinational and global corporations over the last 20 years. Representative rather than exhaustive, even just these ten trends highlight the need in business for consultation that is psychologically-based.

See Table 1 for a listing of these ten trends plus possible consultation services psychologists could provide in response to each trend.

\section{Trend \#1 - The Emergence of Emotional Intelligence ("E.Q.") as a Recognizable, Credible and Valued Concept in Business.}

The emergence of emotional intelligence, also referred to as emotional literacy and "EQ", is one of the most significant developments within the realm of business leadership and executive development in the last decade. Focused on interpersonal effectiveness and intra-personal awareness, this construct took hold with the publication of Goleman's pivotal book Emotional Intelligence (1995). At the top of the NEW YORK TIMES bestseller list for many months, Goleman's work excited business people about the possibility that psychologists, in the words of one of my senior executive clients, "... could sharpen our competitive advantage by teaching us what emotional intelligence is, helping people increase it, and getting them to use it to achieve business objectives."

Wrestling with the demands of leading and managing business organizations in a global arena, business leaders resonate with Goleman's hypothesis that for companies to be successful in the current business climate, employees' innate intelligence, business skills, and the right experiences are not enough. Further, these personal assets are no longer enough for people to keep their jobs or to secure promotions.

According to Goleman (1995, p.3):

"The rules for work are changing. We're being judged by a new yardstick: not just by how smart we are, or by our training and experience, but also by how well we handle ourselves and each other. This yardstick is increasingly applied in choosing who will be hired and who will not, who will be let go and who will be retained, who will be passed over and who will be promoted."

In his second book, Working with Emotional Intelligence (1998), Goleman moved from theory to practice highlighting the specific competencies embedded in the 
concept of emotional intelligence -- what they are, how to recognize them, and most importantly how to increase them for greater leadership effectiveness. In brief there are five primary areas of emotional literacy: (1) self-awareness -- the knowledge of one's internal emotional states, preferences, resources, and intuitions; (2) self-regulation -- the ability to manage one's internal states, impulses, and resources; (3) motivation -- emotional tendencies that guide or facilitate the reaching of one's goals; (4) empathy -- the ability to put one's self in-the-skin of another, i.e. awareness of another's feelings, needs, and concerns; and (5) social skills -- the ability to form relationships and achieve desirable responses from others.

While some might dismiss Goleman's work as a mere weaving of longstanding psychological knowledge and principles, we cannot dismiss his significant accomplishment: the legitimization of the central role the emotional self plays in work-related success or lack of same.

Goleman's success has been so great that it has spawned a new industry focused on emotional literacy. Numerous companies are organizing conferences, conducting research studies, holding seminars, and developing "EQ" metrics and costly certification programs. In addition, a legion of individual "coaches" from an array of backgrounds and often without any formal training in the behavioral sciences are building lucrative consulting practices with the promise that they can increase employees' effectiveness in this new leadership dimension. However, few consultants are as equipped as psychologists to teach, train, and coach in the realm of emotional intelligence.

Finally, the business case for the importance of emotional intelligence is supported by an accumulating body of research. For example, a study conducted by the Center for Creative Leadership (McCall \& Lobardo, 1983) on de-railment among senior executives concluded that deficits in emotional intelligence was the key factor.

\section{Trend \#2 - The Talent War.}

One of the major current workplace challenges is staffing -- ensuring that organizations have the leadership, managerial, and technical talent essential to meet business objectives. Dubbed the "talent war", a complex dynamic of ongoing change, competitive pressures, new demographics, and shifting attitudes about work has intensified the challenge of attracting, retaining, and motivating employees.

A corporate communication piece from a Fortune 100 company captures this situation:

"The competitive environment is tough and not likely to get any easier. We are expected to do more with less and get results even quicker than before. The 
world of work is changing with flattening structures, less obvious career progression, ever tougher targets to achieve with new ways of working. Never has it been more important to focus on motivating and retaining the people we have, as well as attracting new people."

The most effective staffing efforts can be described metaphorically as a threelegged stool (see Figure 1). This approach necessitates equal attention to three core components of a candidate's profile: (1) pedigree (education, certifications, references); (2) relevant experience; and (3) "fit " (behavior profile and the likelihood of being well-assimilated into the culture of the hiring company).

Most companies do an excellent job screening for pedigree. However, researchbased and technology companies, in particular, can be easily seduced into bad hiring decisions by basing these decisions solely on a candidate's outstanding pedigree.

Most companies do a moderately effective job of screening for experience. However, on a subjective experience criterion such as managerial effectiveness, interviewers can be mislead and often produce false positive decisions. This is especially true in the presence of candidates with strong pedigree data, candidates who interview well, and when interviewers are inexperienced in conducting probing, focused interviews.

Few companies -- except those that include psychologists (or others trained in the behavioral sciences) in their selection process -- do an effective job of screening for "fit." The over-arching question when screening for "fit" is: Will this person be able to get along with others and assimilate effectively into this organization culture, as well as drive for results? This person-job-company culture "fit" is a complex alchemy that must begin with clarity about what the essential behavioral norms are in a company (and perhaps even within a specific division of a large company). Candidate profile data is then considered in the context of those behavioral norms, and interviewing is designed to pull relevant information.

While psychologists have a long history of providing this type of consultation, there are a number of current issues (e.g., diversity, cross-cultural considerations, changing demographics and work-related attitudes) that indicate the need for new approaches in this type of consultation. One example of a new approach finds the consulting psychologist as the emotional intelligence content expert creating behaviorally-anchored interview questions to be used by all members of a company interview panel. The consulting psychologist might even become a member of the interview panel and present his/her unique perspective during the decision-making phase of the selection process.

\section{Trend \#3 - Increased Corporate Investment in Leadership Development}


One way in which companies are trying to deal with the talent war issue is by providing more resources for leadership development. This is intended as both a recruitment and retention strategy, as well as a succession planning initiative. Based on a survey of 350 companies, leadership development guru Bennis (Giber, Carter \& Goldsmith 1999, p. xi) states:

"Over the past few years, there has been an explosion of interest in leadership development. Companies have recognized the shortage of talented managers, the importance of building their bench strength, and the need to widen perspectives in order to compete globally."

In his survey of these companies, Bennis learned that (1) less than half of them had a formal process for nominating or developing high-potential employees, and (2) among the companies that did have a formal process, the critical success components included specific training, 360-degree feedback, and exposure to senior executives including mentoring.

Giber, Carter and Goldsmith (1999) in a Linkage Press publication reported on the most valued approaches to leadership development activity. These include: (1) the use of leadership competency models that include behavioral competencies; (2) senior management support of/involvement in leadership development initiatives; (3) the linking of specific training to functional or global rotations, coaching and mentoring; (4) action learning -- engaging people in finding real solutions to real problems; and (5) the creation of a learning community in which senior executives participate as faculty.

Opportunities for psychologists are especially strong in companies where emotional intelligence is being integrated into competency-based leader development models. Examples of such Fortune 500 companies are J\&J, Rohm and Haas Company, and SmithKline Beecham.

\section{Trend \#4 - The Burgeoning Use of Executive Coaching}

The use of one-on-one executive coaching as a leader development tool has increased significantly since the early 1990s. For example, membership in the International Coaching Federation (ICF) - comprised mostly of non-psychologists - grew by $70 \%$ in 1999 (from 1300 to 2200 members).

Kilburg (1996, p. 59) has identified executive coaching as "an emerging competency" in the practice of psychological consultation.

In practice, requests for executive coaching take many forms; i.e., the indications for this type of individual intervention can vary enormously. Therefore, consultants need to conduct a thorough needs assessment to determine the appropriateness of the referral. Upon the determination of the appropriateness of such a referral, the customization of each engagement is central to a successful 
outcome. For example, the needs of an executive seeking coaching assistance to ensure his/her successful assimilation into a new company will differ markedly from an executive who needs to change his/her authoritarian leadership style.

Further, psychologists who become successful executive coaches possess an array of general and specialized skills in addition to foundational psychological expertise. VanFleet (1999) maintains there are certain "general psychological skills" for psychologists to be successful executive coaches. These include excellent interpersonal skills; the ability to listen and show empathy for widely differing groups; patience and the ability to adapt to change; analytical problem solving; creativity; and humor skills

VanFleet also points to certain "specialized skills" as essential for effective executive coaching. These include an appreciation of the complexity of workplace pressures; training and presentations skills; systems-thinking; the ability to visualize and focus on outcomes; practical knowledge of individual, interpersonal and organizational interventions; clinical background (subtleties of human interactions); knowledge of organizational dynamics and development; and expertise in specific areas to include leadership development, group facilitation, and team-building.

Executive coaching opportunities for psychologists are enormous - so much so that coaching might even become a specific proficiency area within psychology. However, there is reason for concern and vigilance. As this type of consultation has proliferated, numerous non-psychologists are providing this service to business people - even when sustained behavior change is the expected outcome.

Brotman etal (1998, p. 40) maintain:

"Psychologists working in the emerging competency area of executive coaching must promote a more complete understanding (among corporate decision makers and prospective clients) of what constitutes effectiveness in this area -particularly when the expected outcome is sustained behavior change.... These educative efforts are essential if executive coaching for sustained behavior change is to be established as a respected consultative area adding value to organizationally-based leadership development initiatives."

Surely there are executive coaching referrals for which non-psychologists would be suitable. These referrals include specific skill-building (e.g. communications, foreign language, etc.) and business or organization structure issues such as strategy development and organization re-design, respectively. However, coaches who have not had training in psychology or in a related behavioral science are less likely to be successful in handling referrals where an executive given current demands of his/her role -- must change deeply entrenched patterns of dysfunctional behavior. Narcissistic leaders are an example of a deeply 
entrenched and dysfunctional behavior pattern. There are many successful business leaders with this profile, and not surprising, they are often referred for executive coaching.

Maccoby (2000, p. 71) writes:

"Given the large number of narcissists at the helm of corporations today, the challenge facing organizations is to ensure that such leaders do not self-destruct of lead the company to disaster. That can take some doing because it is very hard for narcissists to work through their issues - and virtually impossible for them to do it alone. Narcissists need colleagues and even therapists if they hope to break free from their limitations."

One of the most difficult experiences a psychologist coach will encounter is that of trying to get an executive back-on-track in a coaching process after he/she has been mishandled by a non-psychologist coach.

Brotman etal (1998, p.41) state:

"Despite its growing importance, executive coaching remains an unregulated, poorly defined area...Given the costly nature and high profile of executive coaching work, corporate decision makers must be fully informed to be able to hire competent consultants. This is especially true because sustained behavior change is frequently the desired outcome of an executive coaching assignment."

The psychologist-coach must be able to describe a typology of executive coaching services so that he/she can readily convey when psychological expertise is essential to a successful executive coaching outcome.

\section{Trend \#5 - The Shift in Employees' Psychological Orientation to Work}

While this trend is related to the "talent war" issue discussed earlier, it is significant enough to warrant specific focus. The cover photo and headline for a 1998 story in the business publication, Fortune (November 1998) captured the essence of this trend. We see a geeky, bespectacled young man in a tee-shirt with a canary on his head. The headline read, "Hey, corporate America, I want a sign-on bonus, a cappuccino machine, and I want to bring my pet to work. And guess what, you need me."

There are millions of "Gen-Xers" in today's workforce. Compared to the generation preceding it, this is a more nomadic group of people with strong feelings of entitlement. They are not looking for lifetime employment. Many are not willing to work as hard as their parents did. They do not define themselves by what they do. And they don't want to risk divorce or alienation from their children. Instead, they seek a balanced work-family lifestyle, company-provided benefits, and workplace practices that help support this objective. They expect to 
have a reciprocal relationship with their employers and if they don't, they are ready to take their portable skills elsewhere.

While Smart (1999, p. 128) acknowledges differences among Gen Xers regarding their orientation to work, he contends they are really similar to the generations before them. I would say similar but with a level of skepticism that complicates and intensifies managerial challenges.

Smart writes:

"Generation Xers are different in some respects. They don't trust marriage (their parents split up), companies (dad was downsized out of one company, rightsized out of another), and want to be high-tech entrepreneurs. Some are 'career free agents' in careers they control; most are still like their predecessors -- career slaves."

Psychologists can be an invaluable consultative resource as employers try to retain valuable employees and manage the complex dynamics of mistrust, entitlement, lifestyle preferences, and the demand for greater employeeemployer reciprocity.

\section{Trend \#6 - Shifting Demographics - Legitimization of Work-Family Balance Issue}

The shift in workplace demographics is a related factor in the change of employees' psychological orientation to work. These demographic changes include (1) an increase in early retirement; (2) the younger age of senior executives and other key decision makers; (3) the increase of women and other minorities in teams and/or senior management roles; (4) greater global representation on teams; and (5) an increase in dual career couples, grappling with the demands of both child and elder care issues.

Consider these statistics from the Families and Work Institute (Galinsky \& Johnson, 1998, pp. 1-2)

- $85 \%$ of the U.S. workforce now live with family members and thus have family responsibilities

- $62 \%$ of mothers with infants and toddlers are employed

- $68 \%$ of mothers of pre-schoolers and $77 \%$ of school-age children are employed -- and Welfare Reform is pushing these percentages even higher

- Of men who have children under age 18 and wives or partners, $67 \%$ are in dual-earner families

- $69 \%$ of all employed men and women have elder care responsibilities

- Dual-earner families -- less than $10 \%$ of the workforce in 1940; this is the dominant family type currently 
One outcome of these shifting demographics may be a legitimization of the workfamily balance issue such that companies become more aggressive in establishing policies and practices that are more family-friendly. While I hesitate to label this a trend, many human resources colleagues have said substantive corporate response to this issue is essential if companies are going to fare well in their employee recruitment and retention efforts. This should prove to be an especially fruitful realm for psychology-based consultation.

\section{Trend \#7 - The Influence of Information Technology on Workplace Practices}

Living in the midst of our information technology explosion makes it harder to maintain perspective. We do not know all the places - both literally and figuratively - this technology will take us. But we do know its effect on working people is both good and potentially problematic. On the positive side, advances in information technology have fueled the possibility of creative, flexible, and virtual working arrangements that make it possible for more people to hold jobs while managing demanding family situations. Speed of communication and access to a global arena of colleagues and customers are surely other advantages.

Conversely, there are at least three issues that have adverse implications for both relationship-building and personal contentment. First, the proliferating use of voice-mail and e-mail is diminishing the frequency of face-to-face communication. Second, for those who are sarcastic, impatient or otherwise reactive, their "grenades" in the form of e-mail can exacerbate already existing "political" problems. Third, there is the "Internet paradox" -- the role of this information technology in reducing social involvement and psychological wellbeing. Patterson etal $(1998$, p. 877$)$ state:

"Researchers and social critics are debating whether the Internet is improving or harming participation in community life and social relationships...greater use of the Internet was associated with declines in participants' communication with family members in the household, declines in the size of their social circle, and increases in their depression and loneliness."

Psychology should have an increasingly important role to play as companies strive to maximize information technology, and groom emotionally intelligent leaders and managers.

\section{Trend \#8 - Globalization of Business}

The globalization of business has intensified the complexity of people issues. There are country culture factors, local customs, behavioral norms, and the adjustment of ex-patriots and their family members to international job assignments just to name a few. 
Futurist Celente wrote (1997, p. 312):

"On January 1, 2000, it was not yet apparent to everyone that light was being woven into the dark and violent backdrop of destructive and devolutionary trends. Yet it would not be so very long before the golden threads of renaissance thought, emotion, and values took command of the new millennium tapestry. Ideas had changed. People changed. Everything changed. The Global Age was born."

In emphasizing the central importance of strategic intent for effective global business success, Hamel and Prahalad (1994, p. 136) maintained:

"Direction, discovery, and destiny are the tests of any strategic intent. Turning strategic intent into reality requires that every employee understand the exact way in which his or her contribution is crucial to the achievement of the strategic intent."

Change. Lightning speed change. Relentless change. The need to align people quickly with the strategic intent. The potential role of the consulting psychologist cannot be over-estimated when it comes to managing the human reaction to change. Surely psychologists are especially equipped to help manage and normalize the dynamics of change for all employees -- including senior level executives.

\section{Trend \#9 - The Quest for a Creative Retirement}

Another aspect of the demographic shift in corporate America is compression at the senior executive level. Increasingly, senior executives are either electing to retire early or, they are prodded to do so by boards that want fresh leadership and/or need to make way for impatient younger executives who might be lured away by other companies.

Many of these senior executives find themselves grappling with a complicated set of issues and emotions too difficult to sort through and resolve on their own. These include the facts that they (1) intended to work beyond age 60, (2) have not formulated any retirement plans, (3) have few compelling interests other than work, (4) define themselves almost exclusively by their work, (5) want to continue to "work at something" but have little, if any, idea how their skills and experiences might generalize beyond what they have been doing, and (6) have neglected their personal relationships so the prospect of spending more time with these people can be quite anxiety-provoking.

Psychologists have a significant role to play in helping senior executives navigate this lifestage transition successfully. In his discussion of adult development stages Levinson writes (1978, p. 335): 
"The third and final set of tasks has to do with adult individuation. These tasks involve the basic polarities of Young/Old, Destruction/Creation, Masculine/Feminine, and Attachment/Separateness. In transitional periods, a man has the task of reintegrating each polarity in a form appropriate to his new place in the life cycle."

Of men -- and women -- Levinson (1996, p. 421) also wrote:

"The ideas of gender equality and adult development are now in our cultural awareness and have been tentatively placed on our cultural agenda. They also evoke great anxiety and run counter to our traditional ways of thinking. Despite our individual and institutional reluctance to examine them more deeply, we must make the effort to find and smooth a path for the generations of daughters and sons who will come after us."

Psychologists, especially those who are grounded in adult development theory, are uniquely equipped to assist people making pivotal lifestage transitions that are lasting and meaningful. Freed of uncertainty and anxiety as related to work and aging, these people are better equipped and more inclined to smooth the paths for those who will follow them.

\section{Trend \#10 - Greater Focus on Spirituality in the Workplace}

In the context of work, the notion of spirituality is embedded in meaning -meaning in terms of feeling connected with one's self, others, and the world as well as feeling connected to the work itself. Increasingly, a quest for meaning is a focus in my executive coaching engagements. At a time of unprecedented prosperity in America, many are feeling spiritually depleted -- and too fatigued to do much about it. Mitroff and Denton (1999, p. 85) write:

"The word that best captures the meaning of spirituality at work is interconnectedness."

They state further:

"No organization can survive for long without spirituality and soul...we need to integrate spirituality into management. We must examine ways of managing spirituality without separating it from the other elements of management."

Mitroff and Denton are soon to publish a book entitled A SPIRITUAL AUDIT OF CORPORATE AMERICA. According to their research, among the seven things that give people meaning at work is the chance to realize one's full potential. Psychologists should be among the most capable professionals to help people grapple with issues of self-actualization. This is especially true if we have grappled with our own self-actualization challenges. 
Which brings me full circle in this article, and to some brief concluding comments.

\section{CONCLUSION}

Through the confluence of many business events -- especially over the last decade -- psychologists could embark upon a period of activity that would rival and probably surpass what existed in the wake of WW II. Perhaps there is an emotional corollary between the veterans of that war and today's workforce staggering under the pressures of work-related opportunity, familial responsibility, business competition of Darwinian magnitude, and the pain of unrequited aspirations. Even as Wall Street indicators rise and the American economy soars with impressive unemployment and budget surplus statistics, an incalculable level of human pain co-exists with this prosperity.

Whyte (1994, p.3) writes:

"Modern business life arises from a love of the upper world, of material products, of order and organization; it celebrates the material, light-filled portion of existence. It is the world as we see it (or as we would like to see it) and as it most makes sense to us. It has been the basis of our Western affluence, and by the life it has provided many of us, it has much to recommend it. But as many of us suspect, sensing the shock waves now traveling through our corporations and institutions, it is only half the story."

Business needs psychology now more than ever. The ten trends discussed here offer just a small glimpse of the opportunities for psychologists to influence the lives of millions of people -- as well as the success of the companies that employ them. However, if we are to assist business organizations in dealing with these trends effectively, we must deal with ourselves effectively. This may require a reinvention within psychology - a reinvention that rejects turfism and instead fosters the merging of psychological orientations that produces the next generation of powerful interventions.

So let us be bold and imaginative, proactive and synergistic in our approaches to current workplace issues. Given the nature of these issues, let us seize our distinctive place in business consultation. Let us be relentless in our efforts to aid other psychologists who are drawn to this challenging practice area -- for our mutual successes will intensify further opportunities for the role of psychology in business. Finally, let us keep learning what we need to learn from each other as well as from others and whilst on this journey, help ensure that psychology does actualize its full potential in business. 
Table 1

10 TRENDS IN BUSINESS - POSSIBLE CONSULTING OPPORTUNITIES FOR PSYCHOLOGISTS

\begin{tabular}{|c|c|}
\hline $\begin{array}{l}\text { TREND } \\
\end{array}$ & CONSULTING OPPORTUNITIES \\
\hline $\begin{array}{l}\text { \#1 Emergence of "Emotional } \\
\text { Intelligence" }\end{array}$ & $\begin{array}{l}\text { - Coaching leaders } \\
\text { - Teaching (primary, secondary, college and graduate levels) } \\
\text { - Training managers/other employees } \\
\text { - Design/implementation of customized learning programs } \\
\text { - Delivering lectures - business and community settings }\end{array}$ \\
\hline \#2 The "Talent War" & $\begin{array}{l}\text { - Design/implementation of selection processes using psychometrics } \\
\text { - Participation on selection interview panels } \\
\text { - Preparation of candidate profiles - use of psychological assessment } \\
\text { - Developmental feedback to job candidates } \\
\text { - Input to development plans of newly hired employees } \\
\text { - Ongoing consultation to line and HR managers regarding job-person-culture "fit" } \\
\text { - New employee assimilation } \\
\text { - Profiling of key executives in mergers or acquisitions }\end{array}$ \\
\hline $\begin{array}{ll}\text { \#3 } & \text { Increased Corporate } \\
\text { Investment in Leadership } \\
\text { Development }\end{array}$ & $\begin{array}{l}\text { - Design/implementation of leader development initiatives } \\
\text { - Identification of core leadership development competencies } \\
\text { - Proactive career management consultation } \\
\text { - Training executives/managers re how to conduct career development discussions } \\
\text { - Training executives/managers -- how to provide affirmation as well as constructive feedback } \\
\text { - Succession-planning consultation }\end{array}$ \\
\hline $\begin{array}{l}\text { \#4 } \text { Burgeoning Use of } \\
\text { Executive Coaching }\end{array}$ & $\begin{array}{l}\text { - One-on-one coaching } \\
\text { - Consultation to company "internal" coaches } \\
\text { - Triage - referrals to seasoned coaches matched to executive need/contextual factors } \\
\text { - New executive assimilation } \\
\text { - Ongoing executive resource - as objective "sounding board" } \\
\text { - Consultation to executive couples } \\
\text { - Triage for varied resources to relieve work-related stress and work/life tension }\end{array}$ \\
\hline $\begin{array}{l}\text { \#5 Shift in Employees' } \\
\text { Psychological Orientation } \\
\text { to Work }\end{array}$ & \multirow{2}{*}{$\begin{array}{l}\text { - Providing senior HR staff and other executives psychological insights (e.g. feelings of } \\
\text { entitlement, narcissism, motivation) } \\
\text { - Consultation re human resource policies, practices/recommendations for change } \\
\text { - Design of holistic development programs and other company-sponsored wellness } \\
\text { initiatives } \\
\text { - Lectures/seminars on topical family concerns (e.g. child development, learning disabilities, } \\
\text { elder care, attention deficit disorder, etc.) } \\
\text { - Workshops on work-family balance issue } \\
\text { - Organization consultation (surveys, feedback, program design, mentoring, ongoing } \\
\text { consultation) } \\
\text { - Objective, external sounding board } \\
\text { - Triage resource - family member needs }\end{array}$} \\
\hline $\begin{array}{l}\text { \#6 Shifting Demographics - } \\
\text { Legitimization of Work- } \\
\text { Family Balance Issue }\end{array}$ & \\
\hline $\begin{array}{l}\text { \#7 Influence of Information } \\
\text { Technology on Workplace } \\
\text { Practices }\end{array}$ & $\begin{array}{l}\text { - On-site seminars, lectures -- pros and cons of IT } \\
\text { - Proactive strategies for minimizing adverse effects of Internet communication } \\
\text { - Stress reduction } \\
\text { - Triage -- provision of referrals for depression, anxiety, other psychological issues } \\
\text { - Consultation -- viable virtual work models }\end{array}$ \\
\hline \#8 Globalization of Business & $\begin{array}{l}\text { - Ex-Patriot profiling } \\
\text { - Cross-culture sensitivity training } \\
\text { - Spousal/partner counseling } \\
\text { - Cross-culture team-building } \\
\text { - Repatriation consultation } \\
\text { - Violence in the workplace and post-traumatic stress interventions }\end{array}$ \\
\hline $\begin{array}{l}\text { \#9 The Quest for a Creative } \\
\text { Retirement }\end{array}$ & $\begin{array}{l}\text { - Executive coaching - resolution of anger, management of anxiety, focus on } \\
\text { existential issues } \\
\text { - Retirement transition planning } \\
\text { - Profiling of interests, skills, values - implications for meaningful activity } \\
\text { - Executive couple coaching }\end{array}$ \\
\hline $\begin{array}{l}\text { \#10 Greater Focus on } \\
\text { Spirituality in the } \\
\text { Workplace }\end{array}$ & $\begin{array}{l}\text { - Provide resources on what gives people meaning in their work } \\
\text { - Influence thinking of senior line executives } \\
\text {-Workshop design and facilitation } \\
\text { - Triage resource for employees in spiritual } \\
\text { and/or lifestage distress } \\
\text { - Conduct company-sponsored retreats } \\
\text { - Assist employees in creating plans for personal/career revitalization }\end{array}$ \\
\hline
\end{tabular}


Figure 1

THE THREE-LEGGED STOOL

A Model for Staffing Decisions and Development Planning

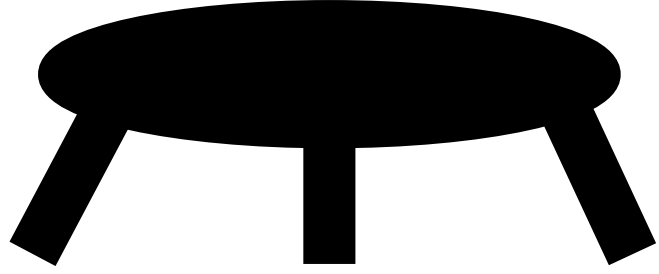

BEHAVIOR

PEDIGREE

To Include:

Education - Degrees

Schools Attended

Technical Training

Certifications

Research Grants

Mentors

Continuing Education

Publications
EXPERIENCE

To Include:

Work History

Special

Assignments

Managerial Skill

Leadership Skill

Industry Specificity

Global Rotation(s)

Management

Training Courses
To Include:

Emotional Intelligence

"Fit" with Company and/or Business Unit

Leadership Style

Harmony with Boss and other Key Stakeholders

Attitude

Aspirations 


\section{References}

Branch, S. (1998). You hired 'em. But can you keep 'em? Fortune, 138(9), 247251.

Broom, N., Brown, S., Jibson, A., Jones, D., Mills, B., Ryan, D., Sanders, J., Severino, E., \& Wolf, B. (1998). Charm our people: eleven ways for you to help consumer healthcare attract retain and motivate. Philadelphia: SmithKline Beecham Consumer Healthcare, L.P.

Brotman, L. E., Liberi, W. P., \& Wasylyshyn, K. W. (1998). Executive coaching: The need for standards of competence. Consulting Psychology Journal: Practice and Research, 50, 40-46.

Celente, G. (1997). Trends 2000: How to prepare for and profit from the changes of the $21^{\text {st }}$ century. New York: Warner Books, Inc.

Galinsky, E., \& Johnson, A. (1998). Reframing the business case for work-life initiatives. New York: Families and Work Institute.

Giber, D., Carter, L. \& Goldsmith, M. (Eds.). (1999). Linkage, Inc's best practices in leadership development handbook. Lexington, MA: Linkage Press.

Goleman, D. (1995). Emotional intelligence. New York: Bantam Books

Goleman, D. (1998). Working with emotional intelligence. New York: Bantam Books.

Hamel, G., \& Prahalad, C. K. (1994). Competing for the future: Breakthrough strategies for seizing control of your industry and creating the markets of tomorrow. Boston: Harvard Business School Press.

Kilburg, R. R. (1996). Executive coaching [Special issue]. Consulting Psychological Journal: Practice and Research, 48, 59-60.

Levinson, D. J. (1978). The seasons of a man's life. New York: Ballantine Books.

Levinson, D. J. (1996). The seasons of a woman's life. New York: Alfred A. Knopf.

Maccoby, M. (2000, January - February). Narcissistic leaders: the incredible pros, the inevitable cons. Harvard Business Review, pp 69-77. 
McCall, M. W., Jr., \& Lombardo, M.M. (1983). Off the track: Why and how successful executives get derailed (Tech. Rep. No 21). Greensboro, NC: Center for Creative Leadership.

Mitroff, I. I., \& Denton, E. A. (1999). A study of spirituality in the workplace. Sloan Management Review, 40(4),83-92.

Patterson, M., Lundmark, V., Kiesler S. \& Mukopdhyay, T. (1998). Internet paradox: A social technology that reduces social involvement and psychological well-being? American Psychologist, 51(9), 872-883.

Smart, B. D. (1999). Topgrading: How leading companies win. Paramus, NJ: Prentice Hall Press.

Suinn, R. M. (1999, September). What if psychology had a revolution? APA Monitor, 30(8), 2.

VanFleet, R. (1999, May). Diversifying psychological practice to industry: Getting started. The Pennsylvania Psychologist Quarterly, pp. 15 \& 24.

Wasylyshyn, K. W., Masterpasqua, F \& Haas, W. (1999, August). Balancing work and family: Research findings and implications for consulting psychologists. Paper presented at the 1999 annual convention of the American Psychological Association, Boston, MA.

Whyte, D. (1994). The heart aroused: Poetry and the preservation of the soul in corporate America. New York: Doubleday.

Wong, P. T. P., \& Frey, P. S. (Eds.). (1998). The human quest for meaning: A handbook of psychological research and clinical applications. Mahwah, $\mathrm{NJ}$ : Lawrence Erlbaum Associates, Inc. 